\title{
The need for a new perspective - creating learning networks for African teachers: change, professional development and ICTs
}

\author{
David Berg and Jeannette Vogelaar \\ UNESCO, Learning Without Frontiers \\ 7, Place de Fontenoy \\ 75352 Paris 07 SP \\ Paris, FRANCE \\ Tele + 331456 80498/81142/82061; Fax + 33145680828 \\ E-mail:d.berg@unesco.org,a.vogelaar@unesco.org \\ URL: http://www.education.unesco.org/lwf
}

\begin{abstract}
The dynamics of today's world require a new approach to learning. Rather then tinkering with the current educational practices aimed at improving the situation, we should approach the current crisis of schooling from a completely different perspective. The need to learn how to learn and to provide multichannel learning opportunities through a variety of flexible delivery mechanism forms the basis of the new perspective. How can we teach teachers how to learn? Ongoing professional development through the establishment of collaborative learning networks promises to provide incentives for change not perceived before. An important driving force behind the professional networks is Information and Communication Technologies, around which UNESCO is developing and implementing a project in Africa, with a pilot in Zimbabwe.
\end{abstract}

\section{Keywords}

Program development, evaluation, lifelong learning, teacher development

Capacity Building for IT in Education in Developing Countries

G. Marshall \& M. Ruohonen (Eds.)

(C) 1998 IFIP. Published by Chapman \& Hall 
'Creating Learning Networks for African Teachers' is a project currently being implemented in the framework of UNESCO's Learning Without Frontiers (LWF) initiative. The project aims to benefit from the emerging powers of modern Information and Communication Technologies (ICT) to stimulate processes of change within the broader objective of rethinking education and learning. The rationale for the project and the opportunities and challenges we are facing with the implementation of pilot activities in Zimbabwe should be of interest to other practitioners.

\subsection{Lifelong learning - learning to live}

Today's world is rapidly moving towards a more open and global society, bringing opportunities for economic growth, peace, human rights and international partnership but also creating new sets of problems related to changing patterns of labour, multicultural societies and environmental disruption. Knowledge is dynamic - what is true today may have no value tomorrow. At the same time, access to information is perceived to be vital to economic development and power. The increasing variety of media sources and growing amount of accessible data create a situation in which the individual or community at the receiver end is increasingly becoming responsible for the selection of relevant, useful and accurate information - a responsibility requiring critical media awareness. While Information and Communication Technologies more and more allow many people to generate and disseminate information, thus playing an active role in the processes of interaction between professionals, laymen, learners, policy makers, peers, etc. - it requires skills, knowledge and access to resources to effectively do so.

Pressures of the contemporary age require people, communities and institutions to continually develop and utilize different kinds of knowledge frameworks, value systems, intelligences and skills in order to make sense of, adapt to and contribute to change in constructive and nonviolent ways. There is a need for people to learn how to deal with the changing demands of our society and, at the same time, develop the capacity that allows them to change in order to take control. Learning has become an essential condition for personal and societal growth and development. For example, the Delors Commission report defines the vision of the coming century as one "in which the pursuit of learning is valued by individuals and by authorities all over the world, not only as a means to an end, but also as an end in itself' (UNESCO, Delors, 1996).

\subsection{Building flexible and open learning environments}

During the second half of this century education received more and more attention as a major factor contributing to development, mainly driven by the thinking represented in the emerging human capital and modernization theories (Fägerlind and Saha, 1983). The attention resulted in expansion of school enrolment and 
increases in educational expenditures in absolute terms on a global level. Such actions have been stimulated and reinforced by international conferences such as the World Conference on Education for All held in Jomtien, Thailand, 1990 and the mid-decade meeting of the International Consultative Forum on Education for All (UNESCOa, June 1996). While these actions have to be applauded for the achievements in achieving higher enrolment figures, we see at the same time how schools increasingly fail to provide the learning opportunities required in today's communities.

Both human capital theory and modernization theory have been criticized for their weak argumentation regarding the role of schooling in development. Fägerlind and Saha (1983) argue that schooling is mostly adaptive in nature and reproduces existing social and economic systems rather than triggering change and development. Apart from theoretical critiques we can observe now, in the late 1990s, that reality has proven us wrong in our belief in the expansion of the school system as such. In the 1970s and 1980s Africa had the highest growth figures in educational enrolment at all levels as well as the highest expenditures for education as a percentage of GNP (UNESCO, 1995). In the 1990s the figures have stagnated or even declined. In Africa more than 200 million adults are illiterate (44\% of the adult population) and the gross enrolment figures in sub-Saharan Africa are 73,1\% for primary level, $23.1 \%$ for secondary and $3.3 \%$ for tertiary level education. We also see increasing numbers of dropouts and alarming high unemployment figures among educated youth. Furthermore, the rapidly increasing enrolment during the 1970 s and 1980s has resulted in ongoing excessive pressures on school systems through increased need for training and retraining of teachers, for more schools, for adaptation of curricula, for more textbooks and learning materials, and for improved communications and administration systems.

The Africa example teaches us that society's learning needs cannot be addressed only by expanding the formal education system but require new ways to look at both access to, and quality of education and learning. Rather then only aiming at the building of more schools and training more teachers to allow for higher enrolment figures, a new perspective is required in which we look at how we can create more open and flexible learning opportunities for all. We argue that it is not so important to have as many people as possible in the classroom. Instead we believe that the focus should be on the creation of learning environments as the Amman Affirmation (UNESCO, 1996a) states:

'Given the trend toward more open societies and global economies, we must emphasize the forms of learning and critical thinking that enable individuals to understand changing environments, create new knowledge and shape their own destinies. We must respond to new challenges by promoting learning in all aspects of life, through all institutions of society, in effect, creating environments in which living is learning.'

The Amman Affirmation provides the basis for shaping a new learning environment and provides us the opportunity to present three interrelated principles underlying UNESCO's Learning Without Frontiers programme. 
The need to learn how to learn

We are living in a world that is dramatically different from the world of just six years ago - the time it takes an individual to complete primary school. The rate of change is so dramatic that it no longer suffices to teach our children what we think is important. Rather than us preparing our children for their life tomorrow, we have to place this task in the hands of the coming generations themselves.

'Whereas in the past, change could be managed through generational processes, each generation preparing the conditions for the next generation to adapt to change, this process has now become an intra-generation one'.

(Visser, 1997b).

The capability to cope with change requires the capacity to learn. It is essential that each person develops a concept of 'self-as-learner'. Learning to learn involves developing oneself to engage in critical reflection and creative thinking. Such processes can be stimulated through approaches that are learner-centred, self-directed and focus on problem- and activity-based learning. A big challenge lies in stimulating the learners' abilities to build and enhance their own knowledge structures that are flexible and adaptable.

\section{Multichannel learning approaches}

People are part of different communities with diverse social and cultural backgrounds and are, at times, exposed to different situations from which one can learn. Children only spend a part of their time in the classroom. In developing countries and also in urban areas of less developed countries, they are watching 3-4 hours of television per day. Teachers often feel they are competing with modern media for children's attention and interest.

Rather then trying to compete, we believe that the teacher can very much benefit from such 'outside' influences in a constructive way. In order to create effective learning opportunities, learning process facilitators should build on experiences and stimulate the development of an integrated model of learning that involves classroom teaching as well as interaction with other learning channels such as family members, others in the community, social experiences, other learners and a variety of media (Anzalone, 1995). Within this framework, teachers should be encouraged to link up more actively with the communities they belong to and build a multichannel learning approach. At the same time, teachers should assist learners in developing a critical eye in judging the varying, and sometimes conflicting, information that the different channels provide.

\section{Flexible delivery mechanisms}

Learning can no longer be viewed as a ritual that one engages in only during the early part of one's life with an occasional refresher course. Instead learning is a continuous necessity and opportunities for learning need to be provided that are more flexible and open to the specific needs of individuals or groups of learners. People should have the opportunity to engage in learning whenever and wherever required without being hindered by barriers such as age, distance, time, social, economic or cultural circumstances. 
The three principles imply an approach to learning that promotes the constructive and active contribution of individuals to their dynamic environments. But the principles also reflect an approach to learning that is able to continually adapt itself to the needs of the learners.

\subsection{Educational reform and teacher development}

If we take the existent school establishment and look at the opportunities there are to really do things different rather then tinker with ongoing practices or, worse, try to do more of the same, we see that teachers are the actors who really are in the position to make things happen, given their central role in the current practice of education. The idea of teachers as change agents is key to many education reform programmes that emphasize the importance of improved teacher training. But such programmes never seem to have the expected results.

Teachers constitute the "largest single group of trained professionals in the world' (UNESCO, 1996b) - a tremendous challenge when we realize that they are also often considered the largest force against change (Visser, 1997a). Fullan describes teacher training as society's missed opportunity:

'Teachers and teacher educators do not know enough about subject matter, they don't know enough about how to teach, and they don't know enough about how to understand and influence the conditions around them. Above all, teacher education - from initial preparation to the end of the career - is not geared towards continuous learning'.

(Fullan, 1993)

Teachers often operate in isolation. They mostly have no opportunity to reflect on their own practice or to exchange experiences and ideas with colleagues due to high work pressure and/or the necessity to have more than one full time job. At the same time, those teachers who are enthusiastic, capable and highly motivated are frustrated with their contribution to change and their chance to have a lasting impact since a supporting and understanding environment often seems to be lacking.

Triggering teachers to initiate processes of change should not involve the imposition of measures by the school management but should be the result of selfmotivated processes of learning by the teachers themselves.

Fullan, Bennet and Rolheiser-Bennet (1990) identify four aspects of the teacher as learner which are crucial in the improvement of classroom practice and functioning of schools as a whole. We would like to go further and argue that the following four aspects promote a process of opening up the classroom as learning environment, merging the activities that take place in surrounding communities with what is happening in school:

- development of the instructional repertoire in teachers - the range of instructional strategies and capability to put to work a variety of learning channels;

- development of reflective practice that facilitates clarity, meaning and coherence for teachers in regards to their functioning and role in the learning process; 
- $\quad$ stimulation of research activities to develop an attitude of investigation and exploration, widening the horizon of the teaching practice beyond the constraints of the classroom;

- promotion of collaboration with colleagues nearby and across long distances to enable teachers to exchange experiences, receive and give ideas, feedback and assistance.

It is not so much the four activities that Fullan and his colleagues see as important which concerns us as it is the fundamental underlying attitude:
'... not just being good at cooperative learning, but at an array of instructional models; not just being involved in a reflective practice project, but being a reflective practitioner; not participating in a research investigation, but conducting constant inquiry; not being part of a peer coaching project, but being collaborative as a way of working'.

(Fullan, Bennet and Rolheiser-Bennet, 1990)

Rather then trying to mould teachers' attitudes along these lines, we should seek for opportunities to let teachers become learners, to challenge them in a process of professional development in order to develop those skills and practices that are most constructive in the learning communities they are part of (i.e., the school and the school's environment). Such processes should not be seen in isolation, but rather as an integrated approach to professional development and educational reform. Teacher development should aim at strategies that stimulate collaboration and partnership between teacher educators, teachers, specialists as well as learners and their parents.

\subsection{ICTs as a catalyst to change - providing opportunities for learning}

Communication and Information Technologies (ICTs) have become an integral part of society in many countries - not only in industrialized countries but more and more on the African continent (Janssen-Reinen and Vogelaar, 1997). Technological developments are contributing to expanding opportunities for engaging in teaching and learning at individual, community and society levels.

Through their potential to facilitate communication and access to information, ICTs can contribute to collaboration and partnership. They are key ingredients in professional development and educational reform. Using applications such as email, computer-mediated conferencing, discussion lists, bulletin boards and the World Wide Web, the new technologies have been shown to create opportunities for:

- collaboration among teachers and their partners to break through their traditional isolation - see, for example, Dimauro and Jacobs, 1995; Lieberman and McLaughlin, 1994; Huberman, 1995; Fullan, Bennet and RolheiserBennet, 1990; 
- $\quad$ partnerships across the globe among children, parents, teachers for international peace and understanding of global issues related to cultural diversity and environmental health - see, for example, international learning projects promoted through Kidlink < http://www.kidlink.org>; the Globe Programme $<$ http://www.globe.gov>; MajaQuest

$<$ http://ed.info.apple.com/education/MAYA/index.html >; Intercultural E-mail Classroom Connections <http://www.stolaf.edu/network/iecc $>$ );

- $\quad$ access to nearly unlimited resources on the Internet and to locally stored information (graphical, audio and text) for the manipulation of materials retrieved or locally produced by users in a variety of ways for presentation purposes, for experimentation purposes, for exploration purposes, herewith enhancing the development of locally relevant learning and teaching materials;

- learner-centred and self-directed learning approaches - see, for example, the Apple Computers of Tomorrow <http:www.research.apple.com/go/acct $>$ ).

We don't believe in ICTs as such. We believe in the creative power of collaborative networks combined with easy access to learning resources which are possible through ICTs. It is in this context that UNESCO has developed the project 'Creating Learning Networks for African Teachers' linking teachers through electronic networks to stimulate educational change. TEACHERS

\subsection{A description}

The project 'Creating Learning Networks for African Teachers' (<http://www.education.unesco.org/educprog/lwf/doc/IAl.html $>$ ) aims to improve the quality of education and learning by connecting teacher training colleges in Africa to each other and to the Information Highway. Specifically the project seeks to enhance their capacity to respond to new challenges to teaching and learning by facilitating and stimulating innovative experiences such as:

- opening up teacher training colleges to the communities by becoming information, communication and learning resources for educational planners and researchers, for teachers and for specific learning communities;

- changing perceptions among educational planners and policy makers, researchers, teacher educators and teachers, to begin seeing themselves as lifelong learners and agents for transformation in multifaceted environment;

- involving teachers and others as learners in a process in which they are not passive receivers of education, but, instead, actively contribute to the definition of their learning needs, the planning and execution of their learning and as such participate in the ongoing process of constructing knowledge useful to themselves and their communities. 
The project, still in its pilot stage, will connect a number of teacher training colleges (four to six in twenty African countries) to the Internet in order to develop local, national and regional networks to initiate activities that focus on:

- enhancing dialogue between teacher training colleges, educational planners and policy makers, researchers and practising teachers on issues related to learning and teaching;

- accessing and assessing information on latest concepts, developments and experiments in the field of learning, teaching and education to enhance professional development, build local knowledge structures and stimulate processes of change;

- $\quad$ stimulating the development of locally adapted and relevant

- curricula, appropriate teaching and learning materials, including print based materials, through group work and groupware by using locally relevant images and sounds (including otherwise inaccessible 'artifacts', in close collaboration with the relevant national education authorities);

- promoting the development and implementation of learning projects targeting different learner groups of the communities.

Through the development of these activities, providing room for creative initiatives of teacher trainers and other parties, the project aims at opening up the school system and developing an approach to learning which is more in line with the needs and requirements of today's African society.

\subsection{Pilot activities in Zimbabwe}

Before implementing the project on a large scale, pilot activities will be initiated in a limited number of countries to assess the feasibility of the proposed activities and to further develop the specific modalities and requirements for hardware, software, connectivity arrangements, networking partners, training, etc. Zimbabwe was selected as a first country for the pilot project and it is currently experimenting with the first phase of the project. The choice of Zimbabwe was based on its advanced connectivity plans and current attempts to improve the overall quality of its educational system.

So far, a team of enthusiastic educators comprising a selection of members of teacher training colleges, the teacher education department at the University of Zimbabwe, and the audio-visual and curriculum development unit within the Ministry of Education have received basic training in the use of the Internet. They have also received computers, which have been installed and connected by specialists from the country. Currently, an electronic discussion group is being set up for thematic discussions on education issues relevant to the specific Zimbabwean context and a national web site is being prepared that will facilitate access to learning resources for Zimbabwean teachers. More advanced applications and collaborative learning projects are expected in time when the users have gained some experience with handling the new technology. 
We would like to end with the following conclusions and observations based on our current experiences with the pilot project in Zimbabwe and other experiences around the world.

An expanded vision on lifelong learning requires a perceptual change among teachers, who must see themselves as learners as well as facilitators of learning processes that focus on developing capacities among learners to construct their own knowledge base for future development. Teacher development programmes should focus on professional growth and educational reform, rather than on knowledge transfer and skill training.

Teacher development could be stimulated through networking and collaboration among peers, researchers and learners. The emerging powers of modern communication and information technologies to enhance communication and facilitate access to information could play and important role in building such partnerships.

Past experiences taught us that introducing ICTs in education is a complex process and success depends not only on the technology itself but also on sets of attitudes and expectations of the different actors involved, as well as on the organizational and managerial context in which the technology is being introduced.

In most developed countries, academic research formed the basis for electronic networking. After its growing success, the commercial sector came in and took over. In most African countries, however, the development and growth of the Internet is a process driven by commercial interests, and specific policies and programmes will be required to ensure democratic participation of the public sector and, in particular, the poorly resourced educational institutions.

The introduction of networking technology in industrialized countries followed the introduction of computers in education. In Africa, however, the processes take place simultaneously, offering both an opportunity to have access to the latest equipment - computers in most Dutch schools, for example, are too old for access to the World Wide Web - and a challenge to address the general lack of basic computer skills among teachers as well as learners.

\section{REFERENCES}

Since the World Wide Web continually expands and changes, we cannot guarantee that at the time of publishing and reading this article the URLs provided here are still valid.

Anzalone, S. (1995) The case for multichannel learning, in Multichannel Learning: Connecting All to Education (ed. S. Anzalone), Education Development Center, Washington, D.C.

Delors, J. (1996) Learning: The Treasure Within. Report to UNESCO of the International Commission on Education for the Twenty-first Century. UNESCO, Paris.

Dimauro, V. and Jacobs, G. (1995) Collaborative electronic networkbuilding. Journal of Computers in Mathematics and Science Teaching, 14(1/2), 119-131. 
Fägerlind, I. and Saha, L.J. (1983) Education and National Development: A Comparative Perspective. Pergamon Press, New York.

Fullan, M. (1993) Change Forces. Probing the Depths of Educational Reform. The Falmer Press, London.

Fullan, M.G., Bennet, B. and Rolheiser-Bennet, C. (1990) Linking classroom and school improvement. Educational Leadership, 47(8), 13-19.

Huberman, M. (1995) Networks that alter teaching: conceptualizations, exchanges and experiments. Teachers and Teaching: Theory and Practice, 1(2), 193-211.

Janssen-Reinen, I. and Vogelaar, J. (1997) Educational change and the role of ICTs. Paper prepared for the workshop on Information and Communication Technologies to Change Education, Zimbabwe, 7-11 April, 1997. Paris, UNESCO.

Lieberman, A. and McLaughlin, M.W. (1994) Networks for educational change: powerful and problematic. Phi Delta Kappan, 63, 673-677.

UNESCO, (1995) World Education Report. UNESCO, Paris.

UNESCO (1996a) Education for all. Achieving the Goal. UNESCO, Paris.

UNESCO (1996b) Strengthening the role of teachers in a changing world: Issues, prospects and priorities. Working paper prepared for the 45 th session of the International Conference on Education, 30 September - 5 October 1996, International Conference Centre, Geneva, Switzerland. UNESCO, Paris.

Visser, J. (1997a) Elements for a vision of where the world of learning is going, in Learning Without Frontiers: Beyond Open and Distance Learning (ed. J. Visser), UNESCO, Paris.

UNESCO.<http://www.education.unesco.org/educprog/lwf/doc/icde/icde.html>

Visser, J. (1997b) Multilingualism in a Pervasive Learning Environment. Paris, UNESCO. <http://www.education.unesco.org/lwf>

Any opinions expressed in this paper are those of the authors and not necessarily those of UNESCO. The mention of specific companies or of certain manufacturers' products does not imply that they are endorsed or recommended by UNESCO in preference to others of a similar nature that are not mentioned.

\section{BIOGRAPHY}

David Berg works as Associate Expert with the Learning Without Frontiers Coordination Unit in UNESCO. After graduation in 1992 from the University of Twente, Department of Educational Science and Technology, he was selfemployed, and produced videos and did consultancy work in the Netherlands. Before joining UNESCO, he worked two years with the World Health Organization in Amman, Jordan. In the multicultural context of international cooperation, David Berg specializes in the design, development, production, evaluation and implementation of materials for learning - from print based materials to interactive computer applications.

Jeannette Vogelaar graduated in 1989 from the University of Twente in The Netherlands, Faculty of Educational Science and Technology, after which she spent time as a consultant in projects in Indonesia and Pakistan, focusing in particular on the professional development of teachers and extension workers. Since 1992, Ms. Vogelaar has been working with UNESCO, first in the sub-regional office in Harare 
and, since 1995, at the UNESCO headquarters with the Learning Without Frontiers coordination unit. 